\title{
Hydrodeoxygenation reaction (HDO) of anisole using FePt bimetallic catalysts
}

\author{
Lucas P. Magalhães*, Karen A. Resende, Daniela Zanchet
}

\begin{abstract}
The hydrodeoxygenation reaction (HDO) represents an important way to upgrade bio-oil, and bimetallic catalysts, as FePt, can play an important role in this process due to the bifunctional mechanism. To evaluate the potential application of these catalysts and the impact of Fe content, the reactions of preferential oxidation of CO (PROX-CO) and HDO were executed in this work. The results shows that, on PROX-CO, $1 \mathrm{Fe}: 1 \mathrm{Pt} / \mathrm{SiO} 2$ has a better perfomance due to the moderate content of Fe compared with $\mathrm{Pt}$ and consequently formation of Fe-Pt alloy in the catalyst. However, for HDO of anisole, the $2 \mathrm{Fe}: 1 \mathrm{Pt} / \mathrm{SiO} 2$ shows the best selectivity to the deoxygenation route, indicating that different catalytic sites are stabilized under each reaction conditions.
\end{abstract}

Key words: FePt catalysts, PROX-CO, HDO

\section{Introduction}

Bio-oil represents a valuable alternative source of energy, but some physical and chemical properties that are undesirable limit its use. The hydrodeoxygenation reaction (HDO) represents an alternative way to upgrade the bio-oil and bimetallic heterogeneous catalysts, such $\mathrm{FePt}$, are potential candidates. In the case of $\mathrm{FePt}$, the presence of a hydrogenating $(\mathrm{Pt})$ and an oxophilic metal (Fe) can favor a bifunctional mechanism, where different active sites participate, or show geometric and electronic effects. In this context, this project studied FePt catalysts supported on silica with variable Fe:Pt ratio to address its impact on activity and selectivity in the HDO of anisol, a model molecule of bio-oil. To get further insights about the catalytic sites, preferential oxidation of CO (PROXCO) also was evaluated.

\section{Results and Discussion}

FePt catalysts were prepared by wet impregnation and labeled $x \mathrm{Fe}: 1 \mathrm{Pt} / \mathrm{SiO}_{2} ; \mathrm{x}=0.5 ; 1 ; 2$ is the molar ratio. The samples were calcined, reduced and passivated ${ }^{1}$. X-ray diffraction (XRD) showed only peaks associated to metallic $\mathrm{Pt}$ (before and after Fe impregnation) slightly shifted to larger angles, which indicates formation of Fe-Pt alloy. The particle size was around 7 $\mathrm{nm}$ and the characterization by ICP OES confirmed the chemical composition close to the nominal values.

Catalytic tests were performed in a tubular fixed bed reactor coupled with a gas chromatograph (GC). PROX-CO (CO:O2: $\mathrm{H}_{2}: \mathrm{He}$ 1:1:70:28 vol) were collected during heating and cooling, as Aragão et $\mathrm{al}^{2}$. The $\mathrm{CO}$ conversion increased with temperature and presented hysteresis and showed better activity during cooling compared to heating. $1 \mathrm{Fe}: 1 \mathrm{Pt} / \mathrm{SiO}_{2}$ was the most active in PROX-CO, indicating that the equilibrium between $\mathrm{Fe}$ and $\mathrm{Pt}$ (1:1) was ideal for this reaction under reducing conditions. As $\mathrm{Fe}$ quantity increased, interaction between $\mathrm{Pt}$ and $\mathrm{Fe}$ (Fe-Pt alloy) contributes to increase the activity. However, excess of $\mathrm{Fe}$ is also harmful on PROX due to the possible blockade of Pt adsorption sites.

HDO of anisole was performed in a similar system, with a liquid pump to feed anisole (anisole $=0,2$ $\left.\mathrm{mL} / \mathrm{h} ; \mathrm{H}_{2}=70 \mathrm{~mL} / \mathrm{min}\right)$. Image 1 shows the conversion and products distribution at $200{ }^{\circ} \mathrm{C}$. It can be observed that parallel to HDO, forming benzene and cyclohexane, the catalysts favor hydrogenation (cyclohexanone) and hydrogenolysis (light gases, <C4). Interesting, by increasing the $\mathrm{Fe}$ content $\left(2 \mathrm{Fe}: 1 \mathrm{Pt} / \mathrm{SiO}_{2}\right)$ the benzene production increased, which is the desirable product of HDO. However, higher content of Fe decreased the conversion. The analysis indicates that under HDO conditions, $\mathrm{FeO}_{\mathrm{x}}$ sites are stabilized and are the binding sites of anisole, whereas $\mathrm{Pt}$ sites are responsible for $\mathrm{H}_{2}$ activation $^{3}$. Without the interface with $\mathrm{FeO}_{x}$ sites, $\mathrm{Pt}$ favors hydrogenation and hydrogenolysis instead of HDO.

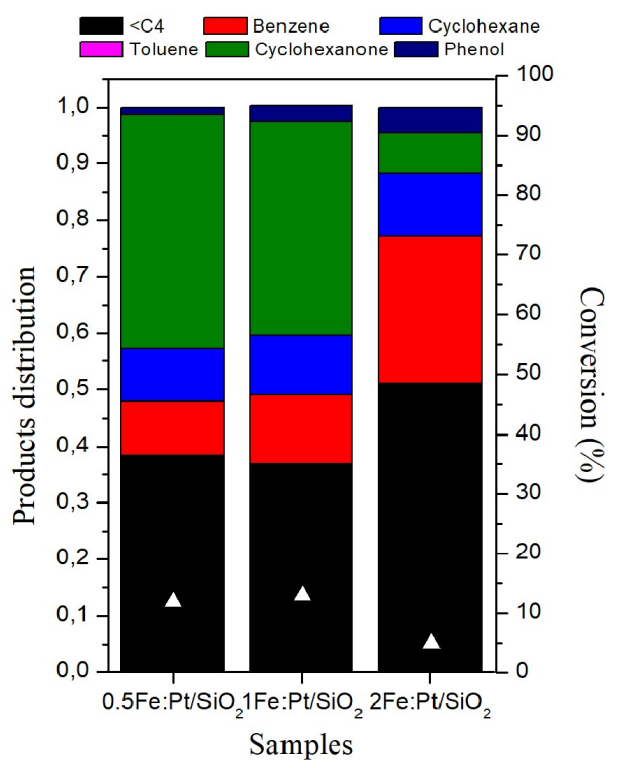

Image 1. Products distribution and conversion on HDO of anisole at $200^{\circ} \mathrm{C}$.

\section{Conclusions}

The Fe content influenced the catalytic performance in both reactions. In HDO, a higher Fe/Pt molar ratio favors benzene production on HDO but reduced the reaction rate and further studies will be necessary to optimize the catalysts performance.

\section{Acknowledgement}

We thank CNPq and FAPESP for the funding.

1 Gomes, I.F.; Fiuza, T.E.R.; Aragão, I.B.; Gonçalves, D.S.; Resende, K.A.; Magalhães, L.P.; Zanchet, D. Brazilian Congress of Catalysis, 2019.

2 Aragão, I.B.; Bueno, J.M.C.; Zanchet, D., Applied Catalysis A: General, 2018, 568, 86-94.

3 Gomes, I.F.; Resende, K.A.; Magalhães, L.P.; Gonçalves, D.S.; Fiuza,

T.E.R.; Zanchet, D., Brazilian Congress of Catalysis, 2019. 